


\section{DISCLAIMER}

Portions of this document may be illegible in electronic image products. Images are produced from the best available original document. 


\section{NOTICE}

This report was prepared as an account of work sponsored by the United States Government. Neither the United States nor the U.S. DOE, nor any of their employees, nor any of their contractors, subcontractors, or their employees, makes any warranty, express or implied, or assumes any legal liability or responsibility for the accuracy, completeness or usefulness of any information, apparatus, product or process disclosed, o. represents that its use would not infringe privately owned rights.

Printed in the United States of America

Available from

National Technical Information Service

U.S. Department of Commerce

5285 Port Royal Road

Springfield, Virginia 22161

Price: Printed Copy $\$ 4.50$; Microfiche $\$ 2.25$ 


\title{
TIME STEP MOTA THERMOSTAT SIMULATION
}

\section{Hanford Engineering Development Laboratory}

\author{
George L. Guthrie
}

September 1978 


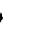


IIME-STEP MOTA THERMOSTAT SIMULATION WITH SEMI-ISOLATED

REGIONS ADJACENT TO THE SODIUM STREAM

\author{
George L. Guthrie
}

\begin{abstract}
$\underline{A B S T R A C T}$
This report details the logic, program layout, and operating procedures for the time-step MOTA (Materials open Test Assembly) thermostat simulation program known as GYRD. It will enable prospective users to understand the operation of the program, run it, and interpret the results.

The time-step simulation analysis was the approach chosen to determine the maximum value gain that could be used to minimize steady temperature offset without risking undamped thermal oscillations.

The advantage of the GYRD program is that it directly shows hunting, ringing phenomenon, and simular events. Programs BITT and CYLB are faster, but do not directly show ringing time.
\end{abstract}




\section{ACKNOWLEDGEMENT}

The author wishes to acknowledge the valuable help of Richard Nygren and J.C. Krogness in troubleshooting, debugging, and running the computer program. 


\section{TABLE OF CONTENTS}

\section{ABSTRACT}

$\underline{\text { Page }}$

FIGURES

I. INTRODUCTION

II. PROGRAM GYRD

A. Theory 5

B. Use of GYRD to Find the Critical Slope 10

C. Program Operation

III. CONCLUSION

17

IV. REFERENCES

19

APPENDIX - PROGRAM LISTING

A-1 


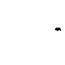




\section{FIGURES}

Figure

Page

1 Schematic of MOTA Test Capsule Layout

2 Block Diagram Giving Flow of Program Logic for Programs Similar to GYRD 


\section{TIME-STEP MOTA THERMOSTAT SIMULATION WITH SEMI-ISOLATED \\ REGIONS ADJACENT TO THE SODIUM STREAM FFO28}

\section{INTRODUCTION}

Th is report details the logic, program layout, and operating procedures for the time-step MOTA thermostat simulation program known as GYRD. The report was written primarily to enable future prospective users to understand the operation of the program, run it, and interpret the results. Explanation of past results is not the purpose of this document.

The MOTA (Materials Open Test Assembly) is a vehicle used for irradiating reactor structural materials specimens in FFTF. A rough drawing of the MOTA is shown in Figure 1 . The MOTA consists of four separate vertical regions: (1) the heaters; (2) the specimens; (3) a free flow space, and (4) the uppermost region which contains the thermostat sensor element and control valve. The outer insulating gap of the MOTA thermally isolates the other parts of the MOTA in the radial direction, from the main coolant stream in the reactor core. The reactor-core coolant circulation pumps maintain a head differential across the MOTA in the vertical direction and this causes an up-flow of sodium. The sodium is heated by the garma heating of the heater rods and specimens in regions (1) and (2), and the temperature of the up-flowing sodium is monitored by the thermostat sensor in Region 4. The sensor controls a valve which regulates the flow of sodium through the MOTA. If the gamma heating increases due to an increase in reactor power leve 1, the temperature of the flowing sodium increases. Th is raises the temperature of the sensor, resulting in a differential opening of the control valve, causing increased coolant flow, lowering the temperature and moderating the error from the intended set point. 

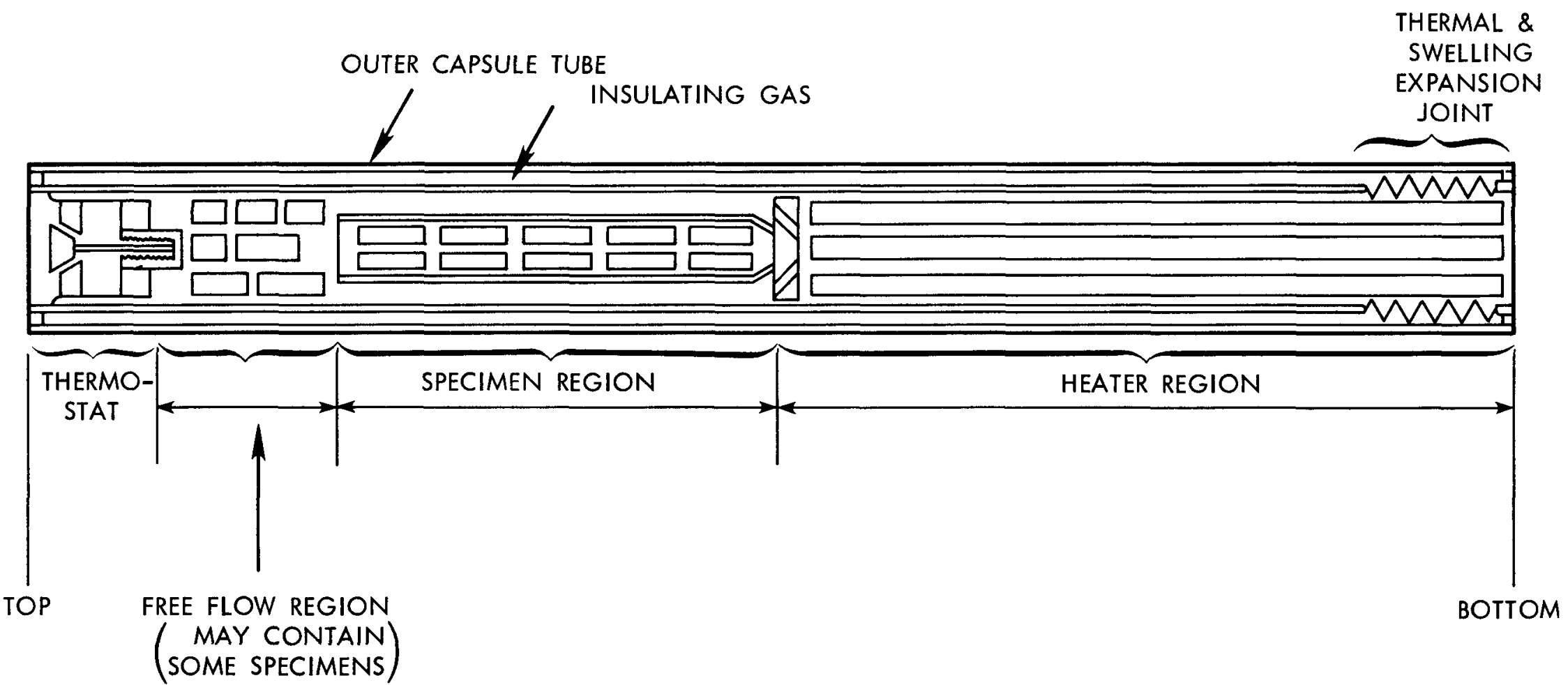

HEDL 7705-180.3

FIGURE 1. Schematic of MOTA Test Capsule Layout. 
For purposes of discussion, we may define a quantity called valve gain, where

$$
\text { Valve gain }=\frac{d(\text { flow })}{d(\text { temperature })}
$$

This quantity is called "SLOPE" in the computer program.

The valve gain has units of $\mathrm{cm}^{3} /{ }^{\circ} \mathrm{C}$ and depends on the thermal expansion properties of the mechanical thermal sensor and the area and slope of the valve seat. The degree of thermal regulation improves and the thermal offset error decreases with increasing valve gain for a given error or offset of the gamma heating of the reactor. However, a very high valve gain may result in thermal oscillations which will damage the valve and subject the irradiation test specimens to undesirable temperature excursions. (The relation between valve gain and regulation has been discussed in a companion document on small sinusoidal signal analysis of the MOTA thermostat. ${ }^{(1)}$ ) One of the primary design problems in planning and constructing the MOTA was determining the maximum valve gain that could be used to minimize steady temperature offset without risking the occurrence of undamped thermal oscillations. Two general approaches are possible: (1) a small sinusoidal signal analys is and (2) a time-step simulation analysis. This report considers the time-simulation approach. 



\section{PROGRAM GYRD}

\section{A. THEORY}

A preliminary examination of the problem disclosed that the vertical transport of heat took place almost exclusively by the mechanism of forced convection of the sodium stream. Consequently, a decision was made to ignore thermal diffusion in the vertical direction. This greatly simplified the problem. A second decision was made to model the radial heat flow at a given vertical level which would occur in the case of an isothermal cell of the flowing sodium connected by a thermal resistor to a single isothermal "isolated region". There were several reasons for this choice. To model a given vertical level by three or more interconnected radial regions would increase the complexity of the programing with increased chances for error. In addition, it would increase the amount of input data required for each separate case being run and would increase the running time both in terms of operator time and machine time. The advantages offsetting this were minimal since the approximation to a continuous radial model was being treated by a companion effort using small signal analysis. (1)

Even with the above approximations, the running time proved to be slow. A significant difficulty was that in any conventional treatment of the time step problem, the time steps had to be small compared to the shortest relaxation time of the components of the problem. That is, if some semi-isolated region on a given vertical level relaxed to the sodium stream in a time on the order of 0.1 seconds, our time steps with conventional techniques were limited to times on the order of 0.05 seconds. The analytical technique described below enabled us to cover a wide range of radial relaxation times without allowing the running time for both the machine and the operator to become a serious concern.

The method of analysis used was that the vertical lengths of the sodium flow cells were not all set equally, but were chosen so that the volumes 
of the flow cells were equal. Then the smooth flow of sodium was approximated by a jumping motion where the sodium jumped discontinuously into the next higher vertical cell after having remained motionless for a period of time equal to the transit time for a particular atom of sodium to completely cross a flow cell in the real motion. According to our model, at the end of the quiescent period, the cells containing "flowing" sodium all passed their complete sodium load to the adjacent cell in the upward vertical direction, accomplishing the sodium transfer instantaneously in zero elapsed time. The incoming sodium in a given flow cell was assumed to arrive in an isothermal condition with a temperature given by the final temperature of the previous time step in the adjacent cell imediately below in the vertical direction. During the residence time of a sodium load in a flow cell, the "isolated" region at the vertical level in question started the time period with an internally isothermal temperature distribution, and the temperature of the isolated region relaxed towards the temperature of the sodium in the flow cell during the quiescent time period. The relaxation continued for the entire quiescent time interval whose magnitude was chosen to give the same average flow rate as that which actually existed in the physically real smooth flow. The radial relaxation involved a simple differential equation that could be integrated for the time increment of the time step. In this way, the time step magnitude is determined only by the time necessary to completely change the sodium in a cell via continuous vertical flow and in no way depends on the thermal time constant of the relaxation of the isolated cell to the flow stream in the radial direction. The temperature history of the two types of cells was as follows. The isolated cell at a given vertical level had a continuous temperature with a discontinuous slope $d T / d t$. It started one time step with the temperature it had attained at the end of the previous time step. The sodium flow cell started a given time step with an initial temperature equal to the final temperature attained by the adjacent flow cell immediately below in the previous time interval. That is, it assumed the temperature of the incoming sodium. 
For the analysis of the temperature history of a particular vertical level during the time interval between sodium interchanges, we need the following definitions:

Let $T_{1}$ be the temperature of the flowing sodium.

$\mathrm{T}_{2}=$ temperature of isolated part of vertical cell.

$c_{1}=$ heat capacity of flowing sodium in the flowing sodium ce 11 .

$C_{2}=$ heat capacity of isolated part of vertical cell.

$G_{1}(x)=$ heat generation rate in flowing sodium, given in watts.

$G_{2}(x)=$ heat generation rate in isolated part of cell. $R=$ thermal resistance between the two parts of the cell.

The two coupled differential equations for the two parts of one vertical level are then:

$$
\begin{aligned}
& \left(T_{2}-T_{1}\right) / R+G_{1}(x)=C_{1} d T_{1} / d t \\
& \left(T_{1}-T_{2}\right) / R+G_{2}(x)=C_{2} d T_{2} / d t
\end{aligned}
$$

If we divide Equation [2] by $c_{1}$, divide Equation [3] by $c_{2}$, and subtract, we obtain

$$
-\frac{1}{R}\left(\frac{1}{C_{1}}+\frac{1}{C_{2}}\right)\left(T_{1}-T_{2}\right)+\frac{G_{1}(x)}{C_{1}}-\frac{G_{2}(x)}{C_{2}}=\frac{d}{d t}\left(T_{1}-T_{2}\right)
$$

If we define

$$
\begin{aligned}
& \left(\frac{1}{C_{1}}+\frac{1}{C_{2}}\right)=\frac{1}{C_{4}}, \\
& \frac{G_{1}(x)}{C_{1}}-\frac{G_{2}(x)}{C_{2}}=G_{3}(x)
\end{aligned}
$$


and

$$
T_{1}-T_{2}=T_{3}
$$

then Equation [4] becomes

$$
-\frac{T_{3}}{R C_{4}}+G_{3}=\frac{d}{d t}\left(T_{3}\right)
$$

We note that the units of $G_{3}$ are not similar to those of $G_{1}$ and $G_{2}$. If we now define

$$
\tau=\mathrm{RC}_{4}
$$

we find

$$
T_{3}=G_{3} \cdot \tau+T_{3,0} \exp (-t / \tau)
$$

where $T_{3,0}$ is defined as

$$
T_{3,0}=\left(T_{1}-T_{2}-G_{3} \tau\right)_{t=0}
$$

Returning to Equations [1] and [2], and adding, we find

$$
G_{1}(x)+G_{2}(x)=\frac{d}{d t}\left(C_{1} T_{1}+C_{2} T_{2}\right)
$$

This allows us to work with a variable $E=C_{1} T_{1}+C_{2} T_{2}$ which can be simply integrated. The calculational scheme at each vertical level then is as follows: 
1. Set the beginning temperature of $T_{1}$, the temperature in the sodium cell, equal to the final temperature attained in the adjacent lower cell at the end of the previous time step.

2. Set the beginning temperature of $T_{2}$, the temperature in the isolated part of the cell, at the temperature value achieved in the same location at the end of the previous time step.

3. Calculate $G_{3}(x)=G_{1}(x) / C_{1}+G_{2}(x) / C_{2}$.

4. Calculate $t$ from the flow rate and sodium cell size.

5. Define $D=T_{1 N}-T_{2 N}$ where the subscript $N$ means "the new value at the time end of the current time step".

6. Calculate $D=G_{3} \tau+T_{3,0}$ exp $(-\Delta t / \tau)$, where $T_{3,0}$ is defined in Equation [11] above.

7. Define $E=T_{1 N} C_{1}+T_{2 N} C_{2}$ and compute $E$ using $E=T_{1} C_{1}+T_{2} C_{2}+\Delta t\left[G_{1}(x)+G_{2}(x)\right]$ where the values of $T_{1}$, and $\mathrm{T}_{2}$ used are those that exist at the beginning of the current time step.

8. Solve $D=T_{1 N}-T_{2 N}$ and $E=T_{1 N} C_{1}+T_{2 N} C_{2}$ simultaneously to obtain

$$
T_{2 N}=\left(E-C_{1} D\right) /\left(C_{1}+C_{2}\right)
$$

and

$$
T_{1 N}=\left(E+C_{2} D\right) /\left(C_{1}+C_{2}\right)
$$




$$
\begin{aligned}
& \text { or } \\
& T_{2 N}+T_{1 N}-D
\end{aligned}
$$

In comparing GYRD, or any of its modifications, to the small signal analysis program BITT, (1) it is important to remember that the relaxation time in GYRD is the time constant for the temperatures in the sodium cell and the isolated cell at a particular level to relax towards each other, while the relaxation time in BITT is the time constant for the relaxation of the temperature of the isolated cell at a particular level to relax to the temperature of a sodium cell where the sodium cell temperature is clamped at a particular fixed temperature value. For purposes of determining the relaxation time for BITT, the sodium cell is thought of as having an infinite heat capacity, which is not true for GYRD.

\section{B. USE OF GYRD TO FIND THE CRITICAL SLOPE}

Program GYRD has been run at various times with a variety of print-out configurations, called by names GYRD, GYDD, GYTL and GEM. All these programs stem from the same basic framework. The programs all have an introductory comment section stored with the program. The block diagram giving the flow of program logic for the basic program appears in Figure 2.

The flow chart is largely self-explanatory. In the usual manner of operation of the program, the reactor power level is set by the subroutine "RAMP" where a value 1.0 indicates full power. Standard usage has been to use a "RAMP" which sets the power to 1.0 for the first seven seconds and then discontinuously elevates the power to a new steady value, 1.0 + "SHOCK" for the remainder of the run. This step increase in power level causes oscillations and hunting. Values of "SHOCK" between 0.001 and 0.1 have been used. After the power step increase occurs, the program user may observe the amplitude and trends of the oscillations. 

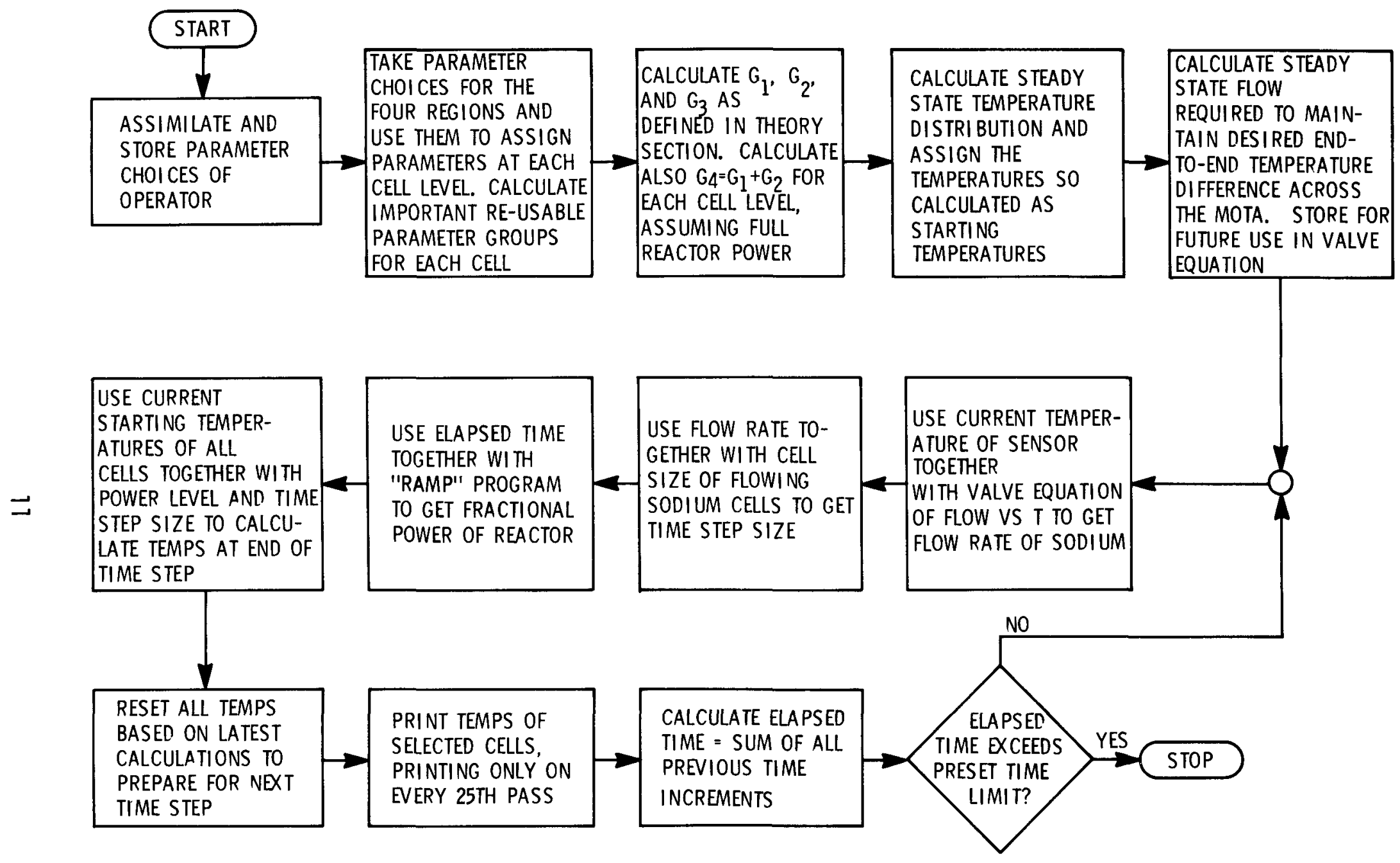

HEDL 7705-180.6

FIGURE 2. Block Diagram Giving Flow of Program Logic for Programs Similar to GYRD. 
For some settings of "SLOPE" (which is the value gain in $\mathrm{cm}^{3} \mathrm{sec} /{ }^{\circ} \mathrm{C}$ ), it is found that oscillations grow, and for other values, the oscillations attenuate. In general, for a given set of parameters (heat capacities, relaxation times, geometry, etc.) there is a critical value of "SLOPE" so that the oscillations damp out to zero if "SLOPE" < "critical slope", and the oscilltions increase without practical limit or have some persisting minimal value if "SLOPE" > "critical slope".

There are exceptions to the above observation. It is possible to have a configuration for which non-oscillatory stability is observed both for low values of "SLOPE" and also for a particular range of higher values of "SLOPE", while use of an intermediate range of "SLOPE", or use of a very high value results in a lack of stability. That is, we may have $0<A<B<C$ and find stability both for SLOPE $<A$, and also for $B<\operatorname{SLOPE}<C$ while oscillations occur for $A<S L O P E<B$ and also for $C<$ SLOPE. This computational result has occasionally been obtained. It should be noted that a value of "SLOPE" greater than "critical slope" may in some cases give a temporarily decreasing amplitude of oscillations after the shock occurs. The oscillations may attenuate to a steady lower level of oscillatory amplitude. The non-linearity of the problem may allow steady state oscillations with the amplitude being a monotonic increasing function of "SLOPE" in ranges of interest, when "SLOPE" > "critical slope". The program user must avoid reaching conclusions based on the short term trend of the amplitude of oscillations immediately following the step increase in gamma level.

\section{PROGRAM OPERATION}

GYRD is listed in the appendix. GYRD was stored at the front of a combined program containing similar programs which differ only in format and content of program output. The second and third lines contain index information for the other versions and these lines are of no interest to the user of GYRD. 
The definitions and terms used in GYRD are given in lines 170 through 340. The quantities G1, G2, and G3 which are evaluated and stored for each ce 11 level in the program correspond to the quantities $G_{1}, G_{2}$, and $G_{3}$ of this report, which follow the original derivations in HEDL-N-1958, pages 146 to 148. The relevant heat capacities carry the labels TTHCP1 and TTHCP2 for the heat capacity of the sodium in the flowing sodium part of the cell, and for the heat capacity of all stagnant items in the cell, corresponding to $C_{1}$ and $C_{2}$ used above in this report, which again follow HEDL-N-1958, pages 146 to 148 . The quantity TTHCP4 in the program corresponds to $C_{4}$ in the derivations above, while TTHCP3 in the program is the total heat capacity of a cell, being the sum of TTHCP1 and TTHCP2. The designation RBR is used in the program for the resistance between the flowing part of the cell and the isolated part of the cell, corresponding to the symbol $\mathrm{R}$ used in the derivations above. Finally, the letter group TAUL is used in the program to represent the relaxation time constant for the relaxation of the temperatures of the two parts of a cell toward a common value.

Several input data items are entered in a single data statement in lines 350 and 360 . The identify of these items becomes apparent in the program and the items are defined in the opening comment section. One of the items which appears to be available as an input data item is the parameter group RBR (resistance between regions). However, this item is recalculated by the program using the relationship RBR = TAUL/TTHCP before the item is used in any calculations. The program treats the heat capacities and the time constants as fundamental items and calculates the thermal resistances from the other two types of items. Thus, the operation of the program is independent of the choice entered for the RBR items (as entered by the operator), and the appearance of RBR in the input list is the result of incomplete historical evolution of the program.

The complete development of the GYRD family of programs is given in notebooks HEDL-N-1978, pages 146 to 154 and HEDL-N-1978, pages 1 through 27 . 
The program terms slope and shock have already been defined. Deltem is the width of the linear region of a flow vs. temperature valvecharacteristic curve that is composed of two horizontal lines connected by a positive sloped linear region. TIMLIM is the time limit on the physical experiment being simulated. ITRIP is a loop counter that keeps track of the number of loops executed since the last printout. (The program suppresses printing on most loops since the operator is not interested in seeing the temperature at each point in time.)

NC is the number of cells in the free flow region, NL is the cell number of the uppermost cell of region three, NM is the cell number of the bottom of region four, NV is the cell number of the elevation which contains the sensor, and $\mathrm{NU}$ is the cell number of the top of region four.

As the program now exists, the first 25 cells are heaters, cells 26 to 52 are specimen cells, the following NC cells comprise region three, and the thermostat region is region four and consists of three cell levels.

The program, in lines 350 to 500 , initializes and stores some input parameter choices. Then it calculates and stores some of the reusable parameter groups for each of the four regions. For region one, this occurs in lines 510 through 640 . For the succeeding regions this happens in lines 650 through 780,790 through 920, and finally, in lines 930 through 1070 where this is accomplished for region 4 .

During this preliminary calculation of reusable parameter groups, the program calculates and stores the heat capacities TTHCP1 and TTHCP2 defined in the program comment statements, and the gamma heating rates G1 and G2 defined above. This is done for each cell and the results are stored. Then in lines 1080 through 1130, the program calculates and stores, for each ce11, the parameter groups G3 and G4 as defined above, as well as the other heat capacity parameter groups needed in the calculations. 
The steady state temperature distribution is calculated in lines 1140 through 1250, and these steady state values are used as the initial settings for the ce 11 parts. The midpoint flow QF of the valve characteristic curve is determined in line 1280, and the initial setting of the sensor temperature occurs in lines 1290 and 1300.

Following the involved original set-up described above, the program enters a loop from lines 1310 to 1690 . In this loop, the program first determines the size of the time step to be taken. It does this by inputting the valve sensor temperature to subroutine CUE which calculates the flow rate using the assumed valve characteristic curve. Then in line 1330 the program uses the common flow-cell volume together with the flow rate to calculate the time step. It then proceeds to use the logic described in the preceding section to calculate the final temperatures of the current quiescent time period. The proper gamma heating rate for the calculation is determined by the subroutine RAMP which requires the elapsed "time" as an input. The valve sensor is assumed to be in constant intimate thermal contact with the "isolated cell" of level $(54+N C)$, which is the middle level of region four. The valve time constant is set indirectly by the choice of relaxation time for region four. It should be noted that for region four, as for all other regions, the relaxation time entered into the program is a relaxation time of two regions relaxing into each other. Thus the relaxation time for the valve sensor to relax to an infinite sink is not a fundamental input parameter but can be varied indirectly by proper choices of the isolated-cell-toflow-cell relaxation time for region four. It is possible to add program lines to allow the use of input relaxation times of the same type as those defined in the small sinusoidal signal analysis programs, but that has not been done to date. It is also fairly easy to change the program to make the valve sensor lag behind the seond flow cell of region four with a separate simple RC-time-constant delay if desired.

After all the updated temperatues have been calculated and reset for the flow cells and isolated cells at each level, and the valve sensor 
temperature has been updated, the program checks to see if the current cycle is one that is to be printed out, and prints (or doesn't) accordingly. Printing occurs on every 24 th loop as set by the parameters in the "IF" statements of lines 1430, 1630 and 1640. The looping process is continued if the simulated elapsed experimental time is less than the TIMLIM set in line 410. If the accumulated experimental time, "TIM" exceeds "TIMLIM", the program stops.

A print line, when it occurs (every 24 th 10op), contains the temperatures of the sodium flow-cells at levels $1,7,14,21,28,35,42,49$ and 56, as we 11 as the temperature of the flowing sodium of the top cell, the temperature of the valve sensor, the elapsed experimental time, and the current value of the flow rate. 


\section{CONCLUSION}

The program GYRD was used with zero valued time constants for the relaxation times between flow and isolated sub-cells on each of the first three levels. In this arrangement it produced results essentially identical to those produced by the simpler program ATYL which uses no isolated regions. The program of this report was run for a variety of inputs and check out satisfactorily against the so-called RC-AC program and BITT which uses small sinusoidal oscillation analysis, together with servomechanism theory.

For most purposes of analyzing for possible instabilities, programs BITT and CYLB are faster but do not directly show ringing time. The advantage of the GYRD type of program is that such a program directly shows hunting, ringing phenomenon, and similar events. 


\section{REFERENCES}

1. G. L. Guthrie, "Small Thermal Oscillation Analys is of the MOTA", HEDL-TME 78-12, Hanford Engineering Development Laboratory, Richland, Washington, September 1978. 
$100=\quad$ PROGRAM GYRD (INPUT TAPES = INPUT ,OUTPUT, TAPE $6=$ OUTPUT)

$110=C I N D E X$ GYRD1 00,2110GYDD2 120,4150GEM4160,61 50́ATYL6160,756ODTYL7570 .9040

120=C FURTHER INDEX GEM1-9050,11130

99)

$130=$ DIMENSION A(99),GFE(99), GNAS(99), T1 (99), T1N(99), T2(99), T2NC

$140=$

$R(99)$

DIMENSION G1 (99), G2 (99), TTHCPI (99), TTHCP2 (99), TTHCP3 (99), RB

$150=$

DIMENSION TAUL (99),DA(28),DX(99), RLI (99)

$160=$

DIMENSI ON G4(99), G3 (99), TTHCP $4(99)$

$170=C$ A IS AREA OF SODIUM FLOW8 GFE IS GRAMS OF STEEL PER CM

180=C GNAS IS GRAMS OF STAGNANT SODIUM PER CM: TI IS TEMP DEG C FLOW $190=C$ IN SODIUM: T2 IS TEMP DEGREES C OF ISOLATED CELL: TTHCPI IS

200:C HEAT CAPACITY OF FLOWING SODIUM IN CELL.: TTHCP2 IS HEAT CAP

$210=C$ OF ISOLATED ITEMS IN CELL: RBR IS RESISTANCE

220=C BETWEEN TWO PARTS OF CELL: RLI IS POSITION OF CENTER OF CELL

230:C RELATIVE TO CENTER OF REACTOR CORE--CMS .: DX IS LENGTH OF

$240=C$ THE CELL-CCMS.: TAUL IS THE TIME CONSTANT FOR THE TWO PARTS

250:C OF THE CELL TO RELAX INTO EACH OTHER.: GI IS THE TOTAL HEAT

260=C GENERATION RATE (GEOMETRY FACTOR ONLY) IN THE FL OWING SODIUM.

$270=c$

$280=C$

$290=C$

$300=C$

$310=\mathrm{C}$

$320=C$

$+2$

$330=\mathrm{C}$

(RE IS THE TOTAL HEAT GENERATION RATE (GEOM FACTOR ONLY) IN

THE ISOLATED PARTS OF THE CELL \& TIN IS THE NEW VALUE OF TI.

T2N IS THE NEW VALUE OF T2.8 DA IS A SET OF DATA ITEMS. THEY

ARE 4 VALUES OF AREA, 4 OF GFE, 4 OF GNAS, 4 OF RBR, 4 OF TAU

BETWEEN CELL PARTS, 4 OF DX, AND 4 GIVING THE NUMBER OF CELLS

IN EACH GROUP.

$340=C$

$350=$

3.503 ,

$360=$

6,25

$380=$

$390=$

$400=$

$410=$

$420=$

$430=$

$440=$

$450=$

$460=$

$470=$

$480=$

$490=$

$500=$

$510=$

$520=$

$530=$

$540=$

$550=$

$560=$

$570=$

$580=$

$590=$

G3 $=G 1 / C 1-G 2 / C 2:$

G4=G1+G2: TTHCP4 IS RECIP OS SUM OF RECIPS I

T THCP $3=\mathrm{Cl}+\mathrm{C2}$

DATA DA/2.087,2.452,8.696,1.587,57.09,23.62,6.718,10.53,0.,

$10 ., 5,17,1, .1,1 ., 1 \ldots, 5,1, . .5,1 ., 2.5472,2.1681, .61133,3,3498$

$227.8 \cdot .3 .1$

SLOPE $=.35$

DEL TEM $=79$.

SHOCK $=.1$

IIMLIM $=200$.

ITRIP $=24$

TEMIN $=350$.

I IM $=0$.

DELTIM $=.1$

NC $=D A(27)$

$N L=52+N C$

$N M=53+N C$

$N U=55+N C$

$N V=54+N C$

DO 16 IA $=1,25$

$\operatorname{DX}(I A)=D A(21)$

RIA $=$ IA

$R L I(I A)=(R I A-0.5) * D A(21)-20 . * 2.54$

$A(I A)=D A(1)$

$G$ FE (IA) $=D A(5)$

BNAS (IA) =DA (9)

$\operatorname{RBR}(I A)=D A(13)$

TAUL (IA) $=D A(17)$ 
$600=$

$610=$

$620=$

$630=$

$640=$

$650=$

$660=$

$670=$

$680=$

$690=$

$700=$

$710=$

$720=$

$730=$

$740=$

$750=$

$760=$

$770=$

$780=$

$790=$

$800=$

$810=$

$820=$

$830=$

$840=$

$850=$

$860=$

$870=$

$880=$

$890=$

900=

$910=$

$920=$

$930=$

$940=$

$950=$

$960=$

$970=$

$980=$

$990=$

$1000=$

$1010=$

$1020=$

$1030=$

$1040=$

$1050=$

$1060=$

$1070=$

$1080=$

$1090=$

$1100=$

$1110=$

$1120=$

$1130=$

CALL GHEAT (GH,RLI (IA))

GI $(I A)=D \times(I A) * A(I A) * .9 * G H$

$G(I A)=D X(I A) *((1 . / 1.3) * G F E(I A)+G N A S(I A)) * G H$

TTHCPI (IA $)=D X(I A) * A(I A) * 1.1295$

16 TTHCPQ (IA) $=D X($ IA $) *(G F E$ (IA)*.58+GNAS (IA)*1.255)

DO 17 I $A=26,52$

$D X(1 A)=D A(22)$

RIA $=I A$

$R L I(I A)=(R I A-25.5) * D A(22)+R L I(25)+0.5 * D X(25)$

$A(I A)=D A(2)$

$\operatorname{GFE}(I A)=D A(6)$

GNAS (IA) $=D A(10)$

$\operatorname{RBR}(I A)=D A(14)$

TAUL (IA) =DA (18)

CALL GHEAT (GH,RLI (IA))

$G I(I A)=D X(I A) * A(I A) * .9 * G H$

$G 2(I A)=D X(I A) *((1 . / 1.3) * G F E(I A)+G N A S(I A)) * B H$

$T$ THCPI (IA) $=D X(I A) * A(I A) * 1.1295$

17 ITHCPZ (IA) $=D X(I A) *(G F E(I A) * .58+G N A S(I A) * 1.255)$

DO 18 I $A=53, \mathrm{NL}$

$D X(I A)=D A(23)$

RIA $=I A$

$R L I(I A)=(R I A-52.5) * D A(23)+R L I(52)+0.5 * D X(52)$

$A(I A)=D A(3)$

GFE (IA) $=D A(7)$

GNAS (IA) $=D A(11)$

$\operatorname{RBR}(I A)=D A(15)$

TAUL (IA) =DA (19)

CALL GHEAT (GH, RLI (IA))

$G I(I A)=D X(I A) * A(I A) * .9 * G H$

$\operatorname{GR}(I A)=D X(I A) *((1, / 1.3) * G F E(A)+G N A S(I A)) * G H$

IIHCPI (IA) $=D X(I A) * A(I A) * 1.1295$

18 T THCP2 (IA) $=D X(1 A) *(G F E(I A) * .58+G N A S(I A) * 1.255)$

DO 19 IA $=N M, N U$

$D X(I A)=D A(24)$

RIA $=I A$

RNC $=$ NC

$R L I(I A)=(R I A-(52.5+R N C)) * D A(24)+R L I(N L)+0.5 * D \times(N L)$

$A(I A)=D A(4)$

$\operatorname{GFE}(I A)=D A(8)$

GNAS (IA) $=D A(12)$

$\operatorname{RBR}(I A)=D A(16)$

TAUL (IA) $=D A(20)$

CALL GHEAT (GH, RLI (IA))

GI $(I A)=D X(I A) * A(I A) * .9 * G H$

$G 2(I A)=D X(I A) *((1, / 1.3) * G F E(I A)+G N A S(I A)) * G H$

TTHCPI (I) $=D \times(I A) * A(I A) * 1.1295$

$19 \operatorname{TIHCPZ}(\mathrm{IA})=\mathrm{DX}(\mathrm{IA}) *($ GFE (IA $) * .58+\operatorname{GNAS}(I A) * 1.255)$

DO $52 \quad I B=1, N U$

$G A(I B)=G I(I B)+G 2(I B)$

$G 3(I B)=G \mid(I B) / T T H C P 1$ (IB) $-G 2$ (IB)/T THCP2 (IB)

ITHCP3 (IB) =T THCPI (IB)+T THCP2 (IB)

T THCP $4(I B)=1 . /(1 . / T \operatorname{THCP} I(I B)+1 . / T$ THCP2 $(I B))$

$52 \operatorname{RBR}(I B)=T A U L(I B) / T T H C P A(I B)$ 


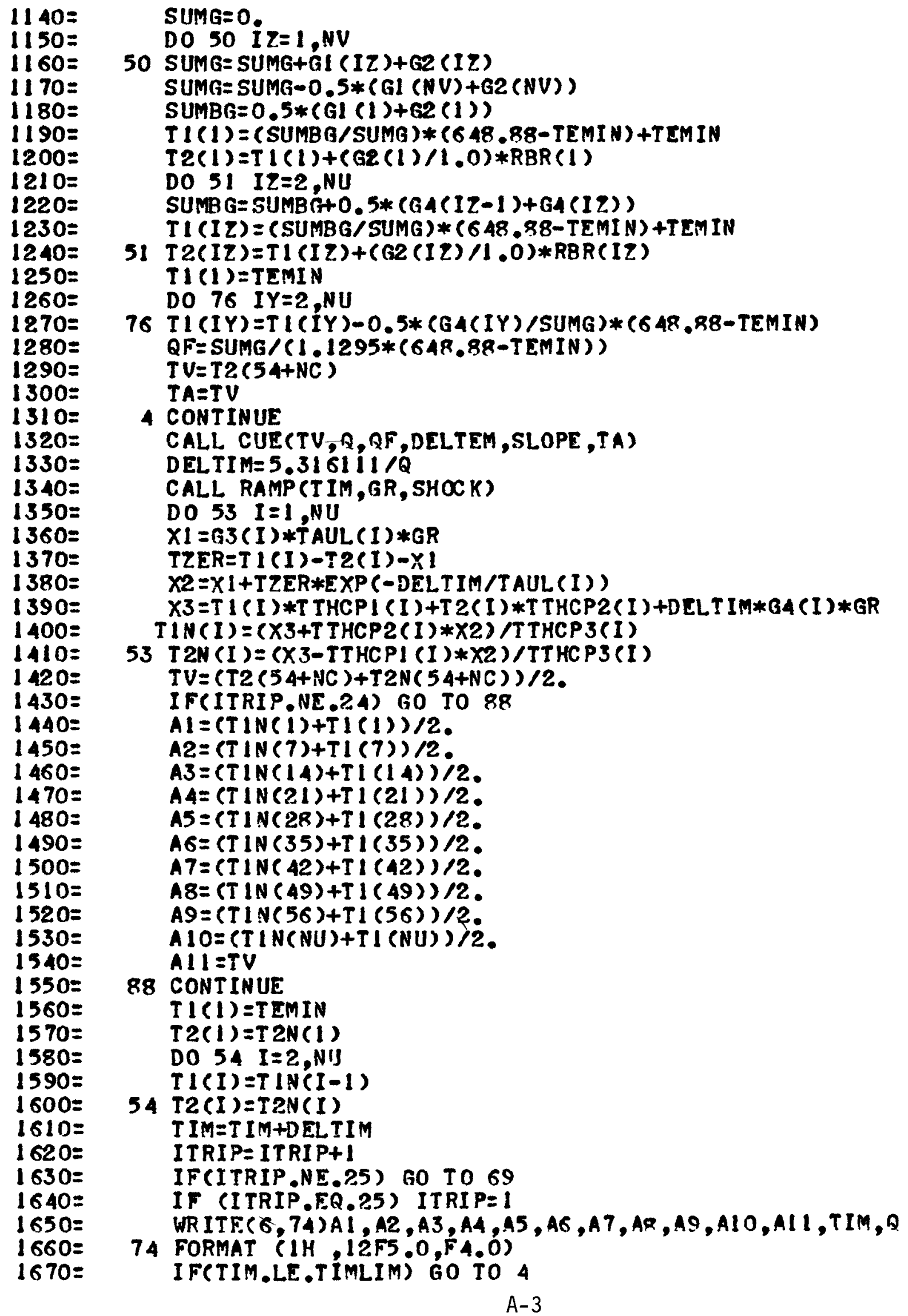




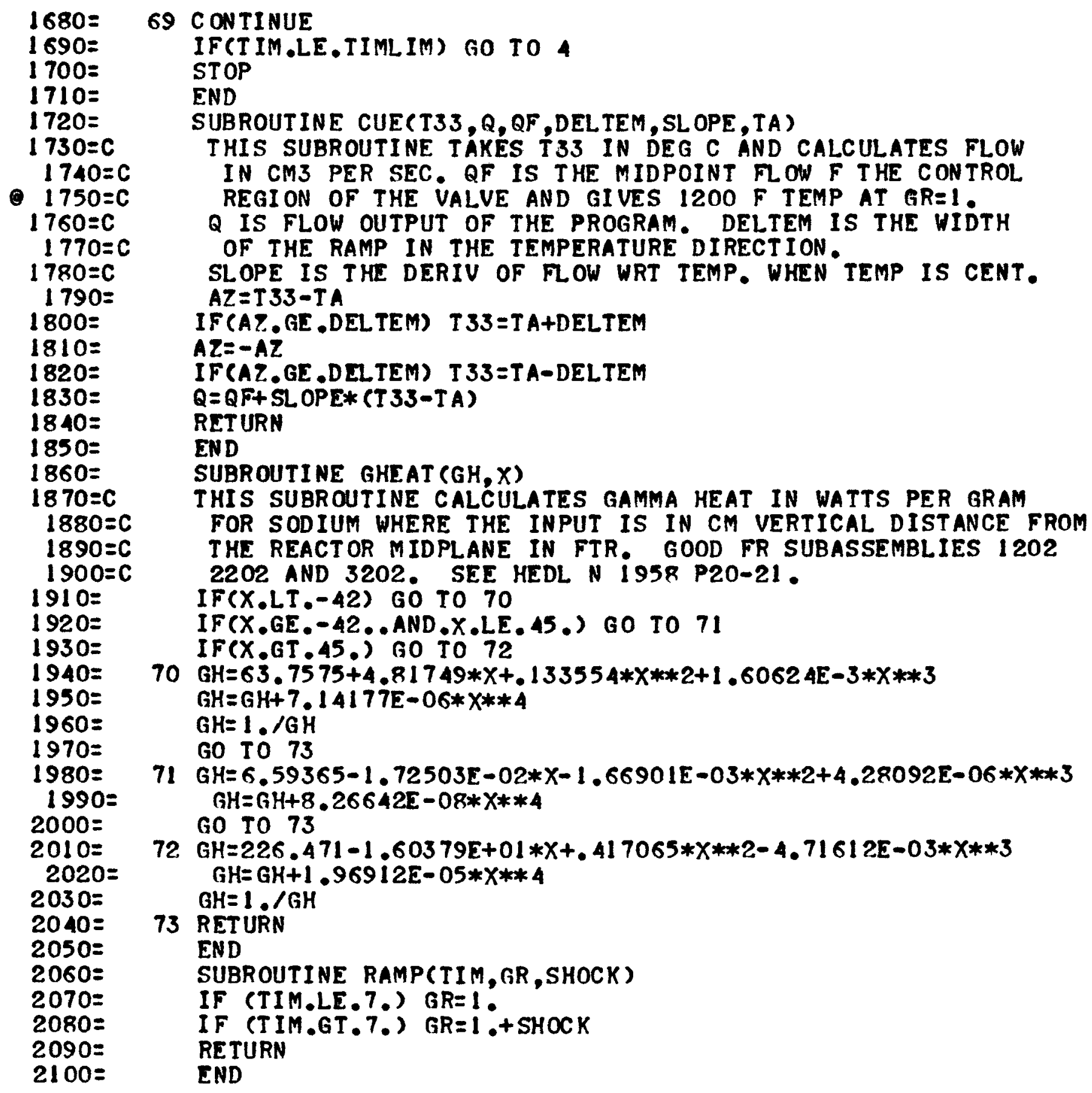

$1940=$

$1950=$

$1960=$

$1970=$

$1980=$

$1990=$

$2000=$

$2010=$

$2020=$

$2030=$

$2040=$

$2050=$

2060=

$2070=$

$2080=$

$2090=$

$2100=$

69 C ONTINUE

IF(TIM.LE.TIMLIM) GO TO 4

STOP

END

SUBROUTINE CUE (T33,Q,QF,DELTEM,SLOPE, TA)

THIS SUBROUTINE TAKES T33 IN DEG C AND CALCULATES FLOW IN CM3 PER SEC. QF IS THE MIDPOINT FLOW F THE CONTROL REGION OF THE VALVE AND GIVES 1200 F TEMP AT GR=1. $Q$ IS FLOW OUTPUT OF THE PROGRAM. DELTEM IS THE WIDTH OF THE RAMP IN THE TEMPERATURE DIRECTION.

SLOPE IS THE DERIV OF FLOW WRT TEMP. WHEN TEMP IS CENT. $A Z=T 33-T A$

IF (AZ,GE.DELTEM) T33=TA+DELTEM

$A Z=-A Z$

IF (AZ,GE,DELTEM) T 33=TA-DELTEM

$Q=Q F+S L O P E *(T 33-T A)$

RETURN

END

SUBROUTINE GHEAT $(G H, X)$

THIS SUBROUTINE CALCULATES GAMMA HEAT IN WATTS PER GRAM

FOR SODIUM WHERE THE INPUT IS IN CM VERTICAL DISTANCE FROM THE REACTOR MIDPLANE IN FTR. GOOD FR SUBASSEMBLIES 1202 2202 AND 3202. SEE HEDL N 1958 P20-21.

IF (X.LT. - 42) GO TO 70

IF (X.GE.-42, AAND,X.LE.45.) GO TO 71

IF (X.GT.45.) GO TO 72

$70 \mathrm{GH}=63.7575+4.81749 * X+.133554 * X * * 2+1.60624 E-3 * X * * 3$

$\mathrm{GH}=\mathrm{GH}+7,14177 \mathrm{E}-06 * X * * 4$

$G H=1 . / G H$

GO TO 73

$71 \mathrm{GH}=6.59365-1.72503 E-02 * X-1.66901 E-03 * X * * 2+4.28092 E-06 * X * * 3$ $G H=G H+8.266425-08 * X * * 4$ GO TO 73

72. $\mathrm{GH}=226.471-1.60379 E+01 * X+.417065 * X * 2-4.71612 E-03 * X * * 3$ $\mathrm{GH}=\mathrm{GH}+1.96912 \mathrm{E}-05 * X * * 4$

$\mathrm{GH}=1, / \mathrm{GH}$

73 RETURN

END

SUBROUTINE RAMP(TIM,GR,SHOCK)

IF (TIM.LE.7.) GR=1:

IF (TIM.GT,7.) GR=1 • +SHOCK

RETURN

END 
UC-79 (206)

UC-79b (41)

DOE-RL (2)

Manager

Chief Patent Attorney

$\underline{D O E / R R T-H Q}$ (2)

Director, Program Division B/107

DOE/FFTF-PO

(5)

Director

HEDL (27)

T.K. Bierlein

A. I. Chow

T.T. Claudson

R.E. Dahl

J.M. Grover

G.L. Guthrie

(2)

J.J. Holmes

J.C. Krogness

J.J. Laidler

W.N. McElroy

R.E. Nygren

H.G. Powers

J.L. Straalsund

H.H. Yoshikawa

Central Files

(10)

$W / A-57$

W/A-106

$W / C-15$

$W / C-20$

W/A-106

W/A-39

W/A-58

W/A-106

W/A-57

W/A-39

W/A-58

$W / C-10$

$W / A-58$

W/A-62

Publication Services

(2) 